\title{
Associations between Patient Global Assessment scores and pain, physical function, and fatigue in rheumatoid arthritis: a post hoc analysis of data from phase 3 trials of tofacitinib
}

Vibeke Strand ${ }^{1}$, Jeffrey Kaine ${ }^{2}$, Rieke Alten ${ }^{3}$, Gene Wallenstein ${ }^{4}$, Annette Diehl ${ }^{5}$, Harry Shi ${ }^{5}$, Rebecca Germino ${ }^{6}$ and Christopher W. Murray ${ }^{5^{*}}$ (1)

\begin{abstract}
Background: Tofacitinib is an oral Janus kinase inhibitor for the treatment of rheumatoid arthritis (RA). We examined the degree to which Patient Global Assessment of Disease Activity (PtGA) was driven by patient-reported assessments of pain (Pain), physical function, and fatigue in patients receiving tofacitinib $5 \mathrm{mg}$ twice daily or placebo, each with conventional synthetic disease-modifying antirheumatic drugs (csDMARDs).

Methods: This post hoc analysis used data pooled from three randomized controlled trials in CSDMARD-inadequate responder (csDMARD-IR) patients (ORAL Scan: NCT00847613; ORAL Standard: NCT00853385; ORAL Sync:

NCT00856544). Using subgroup analysis from $2 \times 2$ tables, associations between PtGA and Pain, Health Assessment Questionnaire-Disability Index (HAQ-DI), and Functional Assessment of Chronic Illness Therapy-Fatigue (FACIT-F) at month 3 were evaluated using Pearson's Phi correlation coefficients. To support the main analysis, associations between select patient-reported outcomes (PROs) were also evaluated in CsDMARD-naïve (ORAL Start; NCT01039688) and biologic (b)DMARD-IR (ORAL Step; NCT00960440) patients.

Results: Across csDMARD-IR treatment groups, low disease activity (defined as PtGA $\leq 20 \mathrm{~mm}$ ), and moderate $(\geq 30 \%)$ and substantial $(\geq 50 \%)$ improvements from baseline in PtGA were associated with mild Pain (Visual Analog Scale score $\leq 20 \mathrm{~mm}$ ), and moderate $(\geq 30 \%)$ and substantial $(\geq 50 \%)$ improvements from baseline in Pain; lack of Pain improvement was associated with little/no improvement in PtGA. In contrast, large proportions of csDMARD-IR patients who reported PtGA improvements did not report HAQ-DI or FACIT-F scores $\geq$ normative values $(\leq 0.25$ and $\geq 43.5$, respectively) or changes in HAQ-DI or FACIT-F scores $\geq$ minimum clinically important difference $(\geq 0.22$ and $\geq 4.0$, respectively). Generally, PtGA and Pain outcomes were moderately-to-strongly correlated at month 3 in csDMARD-IR patients, with weaker correlations evident between PtGA and HAQ-DI/FACIT-F outcomes. Similar findings were generally evident in CSDMARD-naïve and bDMARD-IR patients.

(Continued on next page)
\end{abstract}

\footnotetext{
* Correspondence: Christopher.W.Murray@pfizer.com

${ }^{5}$ Pfizer Inc, Collegeville, PA, USA

Full list of author information is available at the end of the article
}

(c) The Author(s). 2020 Open Access This article is licensed under a Creative Commons Attribution 4.0 International License, which permits use, sharing, adaptation, distribution and reproduction in any medium or format, as long as you give appropriate credit to the original author(s) and the source, provide a link to the Creative Commons licence, and indicate if changes were made. The images or other third party material in this article are included in the article's Creative Commons licence, unless indicated otherwise in a credit line to the material. If material is not included in the article's Creative Commons licence and your intended use is not permitted by statutory regulation or exceeds the permitted use, you will need to obtain permission directly from the copyright holder. To view a copy of this licence, visit http://creativecommons.org/licenses/by/4.0/. The Creative Commons Public Domain Dedication waiver (http://creativecommons.org/publicdomain/zero/1.0/) applies to the data made available in this article, unless otherwise stated in a credit line to the data. 
(Continued from previous page)

Conclusions: This analysis supports the role of Pain as a key driver of PtGA in RA; physical function and fatigue play lesser roles in patients' perceptions of disease activity. These findings corroborate the importance of improved PROs and attainment of low symptom states for optimizing patient care.

Trial registration: Clinicaltrials.gov: NCT00847613 (registered: February 19, 2009); NCT00853385 (registered: March 2 , 2009); NCT00856544 (registered: March 5, 2009); NCT01039688 (registered: December 25, 2009); NCT00960440 (registered: August 17, 2009)

Keywords: Disability, Fatigue, Pain, Patient Global Assessment, Patient-reported outcomes, Physical function, Rheumatoid arthritis, Tofacitinib

\section{Background}

Rheumatoid arthritis (RA) is associated with high levels of pain, impaired physical function, and diminished healthrelated quality of life (HRQoL) [1]. From the patient perspective, improvements in these outcomes remain a priority when evaluating RA treatment strategies [2]. Accordingly, the importance of including patient-reported outcomes (PROs) in randomized controlled trials (RCTs) has long been recognized by professional bodies such as the Outcome Measures in Rheumatology (OMERACT) international consensus effort [3, 4], American College of Rheumatology (ACR) [5], and European League Against Rheumatism (EULAR) [6], as well as the US Food and Drug Administration [7] and payers, such as the Institute for Quality and Efficiency in Healthcare in Germany [8].

One of the most widely reported PROs in RA is the Patient Global Assessment of Disease Activity (PtGA), one of the seven ACR core set components recommended for assessment in RCTs [5, 9]. Important drivers of PtGA include patient assessment of pain (Pain; Visual Analog Scale [VAS]) and physical function (measured by the Health Assessment Questionnaire-Disability Index [HAQ-DI]) [9], both of which are also patient-reported components of the ACR core set [5] known to reflect disease activity [9]. PtGA, Pain, and HAQ-DI are more sensitive to change than laboratory measures, making them a valuable measure of treatment efficacy [10]. Outside the ACR core set, fatigue is also recognized as an important measure in RA RCTs [11], and notably, has been shown to be a further key determinant of PtGA [12]. While physical function $[9,13]$ and fatigue [12] influence PtGA, several studies have identified Pain as the main driver of PtGA, explaining approximately $75 \%$ of the reported results $[9,12-15]$.

Interestingly, discordance between patient and physician assessment of RA has been reported in over a third of RA patients, with patients with discordance typically reporting a higher level of disease activity than their physicians $[14,16]$. Such discrepancies have been shown to negatively impact therapeutic outcomes [9], with discordance contributing to worse HRQoL, activity impairment, and reduced work productivity [17, 18]. Pain appears to be the most important domain to patients, whereas Physician Global Assessment of Arthritis (MDGA) is driven by physician-assessed measures of swollen and tender joint counts (SJC and TJC, respectively) and levels of inflammation markers [9, 14, 17]. As patients tend to weight Pain into PtGA to a greater extent than physicians weight joint counts into MDGA [13], it is unsurprising that Pain has been shown to be a key driver of discordance $[12,13,17,19]$, with associated higher fatigue and disability scores [17].

In recent years, the Janus kinase and signal transducer and activator of transcription (JAK-STAT) pathway has been shown to play a central role in both inflammatory and neurogenic pain processes associated with RA and other autoimmune disorders [20, 21]. As such, blocking elements of JAK-STAT signaling represents an attractive therapeutic strategy [22-24].

Tofacitinib is an oral JAK inhibitor for the treatment of RA. Sustained improvements in PROs, including PtGA, Pain, HAQ-DI, and fatigue (measured using the Functional Assessment of Chronic Illness Therapy-Fatigue [FACIT-F] scale), as well as HRQoL (measured by the 36item Short Form Health Survey [SF-36]) have previously been reported in phase 2 [25], phase 3 [26-30], and phase $3 \mathrm{~b} / 4$ RCTs of tofacitinib [31]. In brief, tofacitinib, administered as monotherapy or combination therapy, resulted in statistically significant improvements from baseline in all five outcomes (PtGA, Pain, HAQ-DI, FACIT-F, and SF-36) versus placebo [25-27, 29, 30] or methotrexate (MTX) [28], that was maintained for the duration of tofacitinib treatment (up to 24 months). Notably, in ORAL Solo, a phase 3 placebo-controlled RCT of tofacitinib in DMARD-inadequate responder (IR) patients, benefits of treatment with tofacitinib monotherapy were shown to be rapid in onset, with significant improvements evident at week 2 in PtGA, Pain, and HAQ-DI, and changes from baseline in PtGA and Pain reported as early as day 3 (after baseline, FACIT-F and SF-36 were not measured until month 3) [26]. Furthermore, in ORAL Strategy, a phase $3 \mathrm{~b} / 4$ head-to-head non-inferiority RCT of tofacitinib monotherapy versus tofacitinib or adalimumab in combination with MTX in MTX-IR RA patients, clinically 
meaningful improvements from baseline in PtGA, Pain, HAQ-DI, FACIT-F, and SF-36 were reported in all three treatment arms [31]. In long-term extension (LTE) studies, tofacitinib, with or without conventional synthetic disease-modifying antirheumatic drugs (csDMARDs; mostly MTX), was associated with sustained improvements in HAQ-DI [32-34].

While improvements in PROs have been demonstrated, the associations between PtGA and Pain, between PtGA and HAQ-DI, and between PtGA and FACIT-F have not previously been investigated in RA patients treated with tofacitinib. This post hoc analysis used pooled data from three phase 3 RCTs of csDMARD-IR RA patients receiving tofacitinib in combination with csDMARDs to further examine and understand the degree to which PtGA is associated with patient-reported improvements in Pain, physical function (HAQ-DI), and fatigue (FACIT-F), and gain insights into these relationships. To support the main analysis, associations between select PROs were also evaluated in csDMARD-naïve (ORAL Start; NCT01039688) [28]) and biologic (b)DMARD-IR (ORAL Step; NCT00960440 [30]) patients.

\section{Methods}

\section{Phase 3 study design}

This post hoc analysis included data from three phase 3 RCTs of tofacitinib with similar designs: 12-month ORAL Sync $(n=795$; NCT00856544) $[29,35]$, ORAL Standard $(n=717$; NCT00853385) $[27,36]$, and 24-month ORAL Scan $(n=797$; NCT00847613) $[37,38]$.

In brief, all three RCTs were conducted globally and enrolled csDMARD-IR (MTX-IR in ORAL Standard and ORAL Scan) patients (aged $\geq 18$ years) with RA according to the ACR 1987 Revised Criteria [39]; active disease was defined as $\geq 6$ tender and $\geq 6$ swollen joints ( $\geq 4$ for each in ORAL Sync; all evaluated using 68/66-joint count) and erythrocyte sedimentation rate (Westergren method) $>28 \mathrm{~mm} / \mathrm{h}$, or C-reactive protein (CRP) level $>7 \mathrm{mg} / \mathrm{L}$. Tofacitinib $5 \mathrm{mg}$ and $10 \mathrm{mg}$ twice daily (BID) and placebo were administered in combination with csDMARDs (specifically MTX in ORAL Standard and ORAL Scan); ORAL Standard also included an active comparator arm (adalimumab $40 \mathrm{mg}$ administered subcutaneously every 2 weeks). Patients receiving placebo combination therapy were advanced in a blinded manner to tofacitinib $5 \mathrm{mg}$ or $10 \mathrm{mg}$ BID if they had not achieved $\geq 20 \%$ improvement in SJC and TJC after 3 months (defined as non-responders); after 6 months, all remaining placebo patients were advanced to tofacitinib.

To support the main analysis conducted in csDMARD-IR patients, additional analyses were conducted using data from csDMARD-naïve and bDMARD-IR patients enrolled in the phase 3 RCTs ORAL Start (NCT01039688) and ORAL Step
(NCT00960440). Full details of the study design have been reported previously $[28,30,40,41]$. Briefly, ORAL Start was a 24-month phase 3 RCT that included csDMARD-naïve RA patients receiving tofacitinib 5 or $10 \mathrm{mg}$ BID monotherapy, or MTX monotherapy $(n=958 ;$ NCT01039688) [28]; ORAL Step was a 6-month RCT that included bDMARD-IR RA patients receiving tofacitinib 5 or $10 \mathrm{mg}$ BID, or placebo (advancing to tofacitinib 5 or $10 \mathrm{mg}$ BID at month 3), all with background MTX $(n=399$; NCT00960440) [30].

All RCTs were conducted in accordance with the Declaration of Helsinki and International Conference on Harmonization Guidelines for Good Clinical Practice and approved by the institutional review board and/or independent ethics committee for each study center. All patients provided written informed consent.

\section{Post hoc analysis}

In this post hoc analysis, data from the three phase 3 RCTs of csDMARD-IR patients were pooled and PtGA, Pain, HAQ-DI, and FACIT-F were assessed at baseline and month 3 (last blinded-placebo controlled time point) for the tofacitinib $5 \mathrm{mg}$ BID and placebo groups. PtGA and Pain were evaluated using a VAS of $0-100 \mathrm{~mm}$. In the supporting analysis, PtGA, Pain, and HAQ-DI were assessed at baseline and month 3 for csDMARD-naïve patients receiving tofacitinib $5 \mathrm{mg}$ BID or MTX as monotherapy, and for bDMARD-IR patients receiving tofacitinib $5 \mathrm{mg}$ BID or placebo, both with background MTX.

For the purposes of the current analyses, low disease activity (LDA) was defined as PtGA score $\leq 20 \mathrm{~mm}$ [42], and moderate and substantial improvements in PtGA were defined as decreases from baseline of $\geq 30 \%$ and $\geq 50 \%$, respectively [43]. Similarly, mild Pain was a score $\leq 20 \mathrm{~mm}$ [42], and moderate and substantial improvements in Pain were defined as decreases from baseline of $\geq 30 \%$ and $\geq 50 \%$, respectively [44, 45]. A clinically meaningful HAQ-DI response was defined as a score of $\leq 0.25$ (normative value) [46] or an improvement from baseline of $\geq 0.22$ (minimum clinically important difference [MCID]) [47]. A clinically meaningful FACIT-F response was defined as a score of $\geq 43.5$ (normative value; based on mean FACIT-F scores observed in two large general population studies $[48,49])$ or an increase from baseline of $\geq 4.0$ (MCID) [50].

\section{Statistical analysis}

Data are presented for the full analysis set (all patients randomized to treatment who received $\geq 1$ dose of study drug and had $\geq 1$ post-baseline assessment).

In the main analysis, subgroup analysis from $2 \times 2$ tables separately evaluated the associations for PtGA and 
Pain, PtGA and HAQ-DI, and PtGA and FACIT-F at month 3, using the respective PRO cut-offs outlined above. In the supporting analysis, subgroup analysis from $2 \times 2$ tables separately evaluated the associations for PtGA and Pain (PtGA-defined LDA with mild Pain; PtGA-defined LDA with substantial $[\geq 50 \%]$ improvement in Pain; substantial PtGA improvements with mild Pain), and PtGA and HAQ-DI (PtGA-defined LDA with HAQ-DI $\geq$ normative values).

At month 3, Pearson Phi correlation coefficients along with $P$ values testing whether the coefficients were significant from 0 were calculated. The $P$ values presented are not adjusted for multiplicity. Generally, correlation coefficient values around $0.3,0.5$, and 0.7 are considered as weak, moderate, and strong positive linear correlations, respectively.

\section{Results}

\section{Patients}

In total, 1133 csDMARD-IR patients were included in this post hoc analysis, of whom 742 received tofacitinib $5 \mathrm{mg}$ BID and 391 received placebo, both in combination with csDMARDs (mostly MTX). Patient demographics and baseline disease characteristics, including PtGA, Pain, HAQ-DI, and FACIT-F scores, were generally similar across both pooled csDMARD-IR treatment groups (Table 1). Patient demographics and baseline disease characteristics of patients in the supporting analysis have been published previously $[40,41]$ and were generally similar among treatment groups within the csDMARD-naïve and bDMARD-IR cohorts.

\section{Patient-reported outcomes at month 3}

The proportions of csDMARD-IR patients reporting each clinically meaningful PRO improvement at month 3 are shown in Table 2. Across all endpoints, responses were numerically higher in patients treated with tofacitinib $5 \mathrm{mg}$ BID versus placebo; these differences were particularly marked for PtGA and Pain. Over 60\% of patients treated with tofacitinib $5 \mathrm{mg}$ BID reported moderate improvements ( $\geq 30 \%$ decrease from baseline) in PtGA and Pain, with a large proportion $(>40 \%)$ also reporting substantial improvements $(\geq 50 \%$ decrease from baseline) across PtGA and Pain. Approximately $35 \%$ of tofacitinib-treated patients reported a mild Pain score (VAS score $\leq 20 \mathrm{~mm}$ ) and approximately $20 \%$ of patients reported HAQ-DI and FACIT-F scores $\geq$ normative values, while $>50 \%$ of tofacitinib-treated patients reported improvements in HAQ-DI and FACIT-F scores $\geq$ MCID.

The proportions of csDMARD-naïve and bDMARDIR patients reporting each clinically meaningful PRO improvement at month 3 are shown in Supplementary Table 1 . Responses were generally numerically higher in
Table 1 Demographics and baseline disease characteristics of CSDMARD-IR patients included in the post hoc analysis

\begin{tabular}{|c|c|c|}
\hline $\begin{array}{l}\text { Demographic or } \\
\text { baseline } \\
\text { characteristic }^{\mathrm{a}}\end{array}$ & $\begin{array}{l}\text { Tofacitinib } 5 \mathrm{mg} \text { BID + } \\
\text { csDMARDs } \\
(N=742)\end{array}$ & $\begin{array}{l}\text { Placebo }+ \\
\text { csDMARDs } \\
(N=391) \\
\end{array}$ \\
\hline Age (years), mean (range) & $53.1(18-86)$ & $52.4(18-81)$ \\
\hline Female, $n(\%)$ & $625(84.2)$ & $314(80.3)$ \\
\hline \multicolumn{3}{|l|}{ Smoking, $n(\%)$} \\
\hline Never smoked & $511(68.9)$ & $260(66.5)$ \\
\hline Smoker & $96(12.9)$ & $74(18.9)$ \\
\hline Ex-smoker & $135(18.2)$ & $55(14.1)$ \\
\hline $\begin{array}{l}\text { Duration of RA } \\
\text { (years), mean (range) }\end{array}$ & $8.0(0.2-43.0)$ & $8.8(0.3-49.4)$ \\
\hline $\begin{array}{l}\text { DAS28-4(ESR) score, } \\
\text { mean (SD) }\end{array}$ & $6.4(1.0)$ & $6.3(1.0)$ \\
\hline TJC, mean (SD) & $25.1(14.7)$ & $24.7(14.0)$ \\
\hline SJC, mean (SD) & $14.8(9.2)$ & $14.8(8.7)$ \\
\hline $\mathrm{ESR}(\mathrm{mm} / \mathrm{h})$, mean $(\mathrm{SD})$ & $50.1(25.7)$ & $50.2(24.6)$ \\
\hline RF-positive, $n(\%)$ & $630(84.9)$ & $325(83.1)$ \\
\hline $\begin{array}{l}\text { PtGA VAS score }(\mathrm{mm}) \text {, } \\
\text { mean (SD) }\end{array}$ & $58.3(23.0)$ & $55.0(22.5)$ \\
\hline $\begin{array}{l}\text { Pain VAS score }(\mathrm{mm}) \\
\text { mean }(\mathrm{SD})\end{array}$ & $57.7(23.0)$ & $55.2(22.5)$ \\
\hline HAQ-DI score, mean (SD) & $1.4(0.7)$ & $1.3(0.7)$ \\
\hline FACIT-F score, mean (SD) & $29.0(10.7)$ & $30.6(10.2)$ \\
\hline SF-36 PCS score, mean (SD) & $33.1(7.9)$ & $33.7(7.5)$ \\
\hline SF-36 MCS score, mean (SD) & $40.6(11.9)$ & $42.6(11.5)$ \\
\hline MDGA VAS score, mean (SD) & $59.2(16.9)$ & $58.0(16.9)$ \\
\hline Concomitant therapy, $n(\%)$ & $742(100.0)$ & $391(100.0)$ \\
\hline Oral corticosteroids, $n$ (\%) & $479(64.6)$ & $246(62.9)$ \\
\hline Non-MTX csDMARDs, $n(\%)$ & $152(20.5)$ & $75(19.2)$ \\
\hline MTX, $n(\%)$ & $677(91.2)$ & $354(90.5)$ \\
\hline $\begin{array}{l}\text { Concomitant MTX } \\
\text { dose (mg), mean (range) }\end{array}$ & $14.3(1.4-25.0)$ & $14.9(1.0-25.0)$ \\
\hline
\end{tabular}

Data presented for the full analysis set

Abbreviations: BID twice daily, CSDMARD conventional synthetic diseasemodifying antirheumatic drug, DAS28-4(ESR) Disease Activity Score in 28 joints, ESR, ESR erythrocyte sedimentation rate,

FACIT-F Functional Assessment of Chronic Illness Therapy-Fatigue, HAQ-DI Health Assessment Questionnaire-Disability Index, IR inadequate responder, MCS Mental Component Summary, MDGA Physician Global Assessment of Arthritis, MTX methotrexate, PCS Physical Component Summary, PtGA Patient Global Assessment of Disease Activity, RA rheumatoid arthritis, RF rheumatoid factor, SD standard deviation, SF-36 36-item Short Form Health Survey, SJC swollen joint count, TJC tender joint count, VAS Visual Analog Scale ${ }^{a} n$ values for individual characteristics may vary

csDMARD-naïve patients receiving tofacitinib $5 \mathrm{mg}$ BID monotherapy versus MTX monotherapy, and in bDMARD-IR patients receiving tofacitinib $5 \mathrm{mg}$ BID with MTX versus placebo with MTX. In tofacitinibtreated csDMARD-naïve patients, approximately $46 \%$ of patients reported substantial improvements $(\geq 50 \%$ decrease from baseline) in PtGA, 50\% reported substantial improvements in Pain, and approximately 30\% reported 
Table 2 Proportion of cSDMARD-IR patients reporting each clinically meaningful PRO improvement at month 3

\begin{tabular}{|c|c|c|}
\hline PRO, $n(\%)$ & $\begin{array}{l}\text { Tofacitinib } 5 \mathrm{mg} \text { BID } \\
\text { + csDMARDs }(N=695)\end{array}$ & $\begin{array}{l}\text { Placebo + csDMARDs } \\
(N=366)\end{array}$ \\
\hline \multicolumn{3}{|l|}{ PtGA } \\
\hline LDA (PtGA VAS score $\leq 20 \mathrm{~mm}$ ) & $216(31.1)$ & $62(16.9)$ \\
\hline Moderate PtGA improvement ( $\geq 30 \%$ decrease from baseline) ${ }^{a}$ & $421(60.8)$ & 119 (32.6) \\
\hline Substantial PtGA improvement ( $\geq 50 \%$ decrease from baseline) ${ }^{a}$ & $301(43.5)$ & $73(20.0)$ \\
\hline \multicolumn{3}{|l|}{ Pain } \\
\hline Mild Pain (VAS score $\leq 20 \mathrm{~mm}$ ) & $246(35.4)$ & $62(16.9)$ \\
\hline Moderate Pain improvement ( $\geq 30 \%$ decrease from baseline $)^{a}$ & $419(60.5)$ & $124(34.0)$ \\
\hline Substantial Pain improvement ( $\geq 50 \%$ decrease from baseline) $)^{a}$ & $310(44.8)$ & $70(19.2)$ \\
\hline \multicolumn{3}{|l|}{ HAQ-DI } \\
\hline HAQ-DI score $\geq$ normative value $(\leq 0.25)$ & $142(20.4)$ & $44(12.0)$ \\
\hline HAQ-DI change $\geq$ MCID ( $\geq 0.22$ improvement from baseline) ${ }^{b}$ & $463(66.8)$ & $166(45.6)$ \\
\hline \multicolumn{3}{|l|}{ FACIT-F } \\
\hline FACIT-F score $\geq$ normative value $(\geq 43.5)^{c}$ & $138(19.9)$ & $46(12.6)$ \\
\hline FACIT-F change $\geq$ MCID ( $\geq 4.0$ improvement from baseline $)^{d}$ & $381(55.0)$ & 131 (36.1) \\
\hline
\end{tabular}

Abbreviations: BID twice daily, csDMARD conventional synthetic disease-modifying antirheumatic drug, FACIT-F Functional Assessment of Chronic Illness TherapyFatigue, HAQ-DI Health Assessment Questionnaire-Disability Index, IR inadequate responder, LDA low disease activity, MCID minimum clinically important difference, PRO patient-reported outcome, PtGA Patient Global Assessment of Disease Activity, VAS Visual Analog Scale

${ }^{a}$ Tofacitinib $5 \mathrm{mg}$ BID + csDMARDs, $N=692$; placebo + csDMARDs, $N=365$

${ }^{\text {b } T o f a c i t i n i b ~} 5 \mathrm{mg}$ BID + csDMARDs, $N=693$; placebo + csDMARDs, $N=364$

'Tofacitinib $5 \mathrm{mg}$ BID + csDMARDs, $N=694$; placebo + csDMARDs, $N=365$

${ }^{\mathrm{d}}$ Tofacitinib $5 \mathrm{mg}$ BID + csDMARDs, $N=693$; placebo + csDMARDs, $N=363$

HAQ-DI scores $\geq$ normative values. In tofacitinibtreated bDMARD-IR patients, approximately $38 \%$ and $44 \%$ of patients reported substantial improvements in PtGA and Pain, respectively, and 16\% reported HAQ-DI scores $\geq$ normative values.

\section{Associations between patient-reported outcomes at month 3}

At month 3, the proportion of csDMARD-IR patients reporting PtGA-defined LDA (VAS score $\leq 20 \mathrm{~mm}$ ) with either mild pain (VAS score $\leq 20 \mathrm{~mm}$ ) or moderate $(\geq 30 \%)$ or substantial $(\geq 50 \%)$ improvements in pain ranged from 86.0 to $91.6 \%$ in patients receiving tofacitinib and from 69.4 to $80.7 \%$ in patients receiving placebo. Similarly, a substantial proportion of patients receiving tofacitinib (53.4 to $88.3 \%$ ) or placebo (75.6 to 95.4\%) reported neither LDA nor any of the three Pain outcomes (Fig. 1a-c). In general, similar trends were evident when data were stratified by moderate $(\geq 30 \%$ decreases from baseline; Fig. $2 \mathrm{a}-\mathrm{c})$ and substantial $(\geq 50 \%$ decreases from baseline; Fig. 3a-c) improvements in PtGA. An exception to this was observed with moderate PtGA improvements and mild Pain: numerically lower proportions of patients receiving tofacitinib (51.7\%) and placebo (39.5\%) reported both of these outcomes compared with the other PtGA and Pain outcomes. The proportions of patients reporting each outcome alone are presented in Supplementary Figs. 1a-c to 3a-c (see Additional file 1).
In comparison with analyses of LDA and Pain outcomes, lower proportions of csDMARD-IR patients reported both LDA and scores $\geq$ normative values in either HAQ-DI $(\leq 0.25)$ or FACIT-F $(\geq 43.5)$ in the tofacitinib $(37.0 \%$ and $40.5 \%$, respectively) and placebo (29.0\% and $33.9 \%$, respectively) groups (Fig. 1d-e). In line with analyses of LDA and Pain outcomes, a substantial proportion of patients reported neither LDA nor normative values in either HAQ-DI or FACIT-F in the tofacitinib (87.1\% and $89.4 \%$, respectively) and placebo $(91.5 \%$ and $91.8 \%$, respectively) groups. These trends were also evident when data were stratified by moderate (Fig. 2d-e) and substantial PtGA improvements (Fig. 3d-e). The proportions of patients reporting each outcome alone are presented in Supplementary Figs. 1$3 \mathrm{~d}$ and $\mathrm{f}$ (see Additional file 1).

In comparison with analyses of LDA and Pain outcomes, lower proportions (although still a majority) of csDMARD-IR patients reported both LDA and improvements from baseline $\geq$ MCID in either HAQ-DI $(\geq 0.22)$ or FACIT-F $(\geq 4.0)$ in the tofacitinib $(79.6 \%$ and $65.0 \%$, respectively) and placebo $(61.3 \%$ and $47.5 \%$, respectively) groups (Supplementary Fig. 4 in Additional file 1). Similarly, compared with analyses of LDA and Pain outcomes, lower proportions of patients reported neither LDA nor improvements from baseline $\geq$ MCID in either HAQ-DI or FACIT-F in the tofacitinib $(39.0 \%$ and $49.5 \%$, respectively) and placebo $(57.6 \%$ and $66.2 \%$, respectively) groups. In 


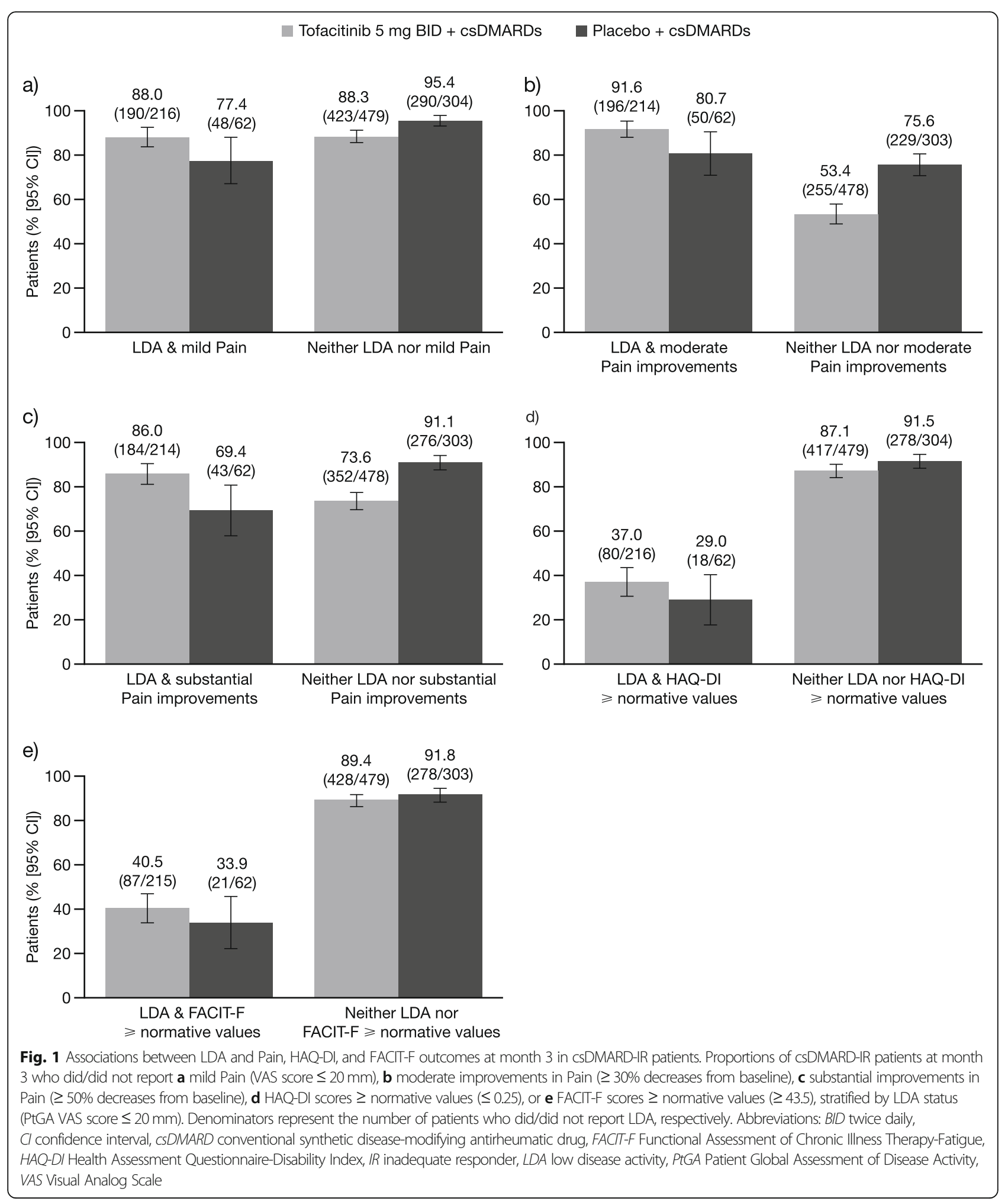

general, similar trends were seen when data were stratified by moderate and substantial PtGA improvements (Supplementary Figs. 5-6 in Additional file 1). The proportions of csDMARD-IR patients reporting each outcome alone are presented in Supplementary Figs. 1-3e and g (see Additional file 1).

In general, Figs. 1, 2, and 3 had the expected symmetrical appearance, with the tofacitinib-treatment group 


\section{Tofacitinib 5 mg BID + csDMARDs a Placebo + csDMARDs}
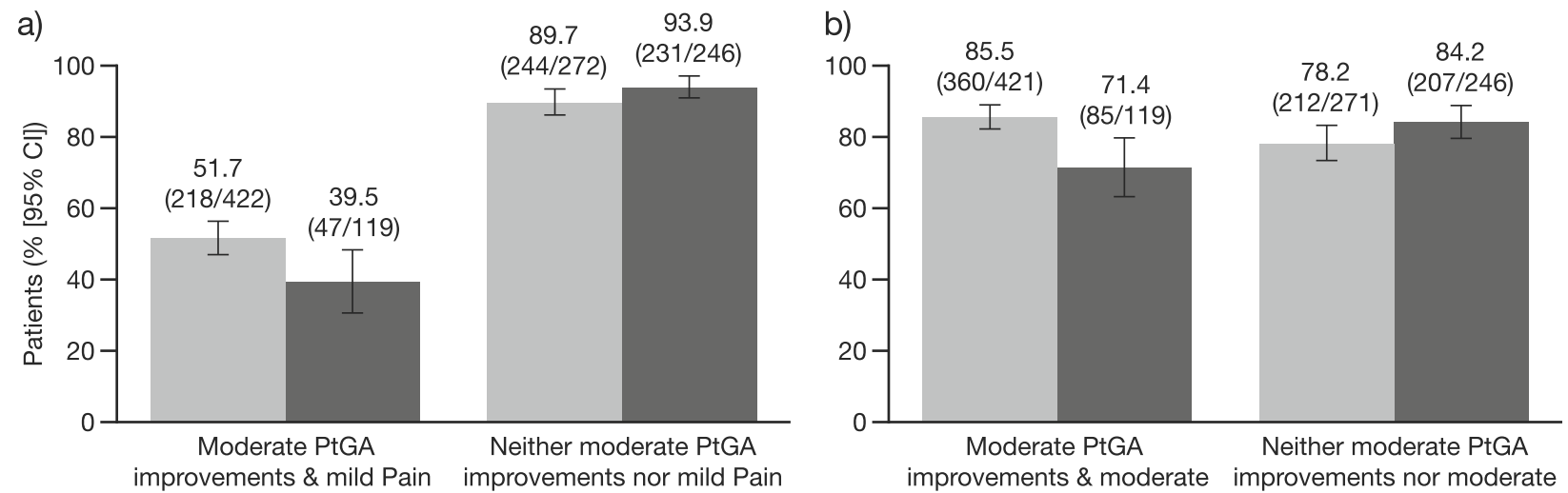

improvements \& mild Pain improvements nor mild Pain

Moderate PtGA

Neither moderate PtGA improvements \& moderate improvements nor moderate

Pain improvements Pain improvements
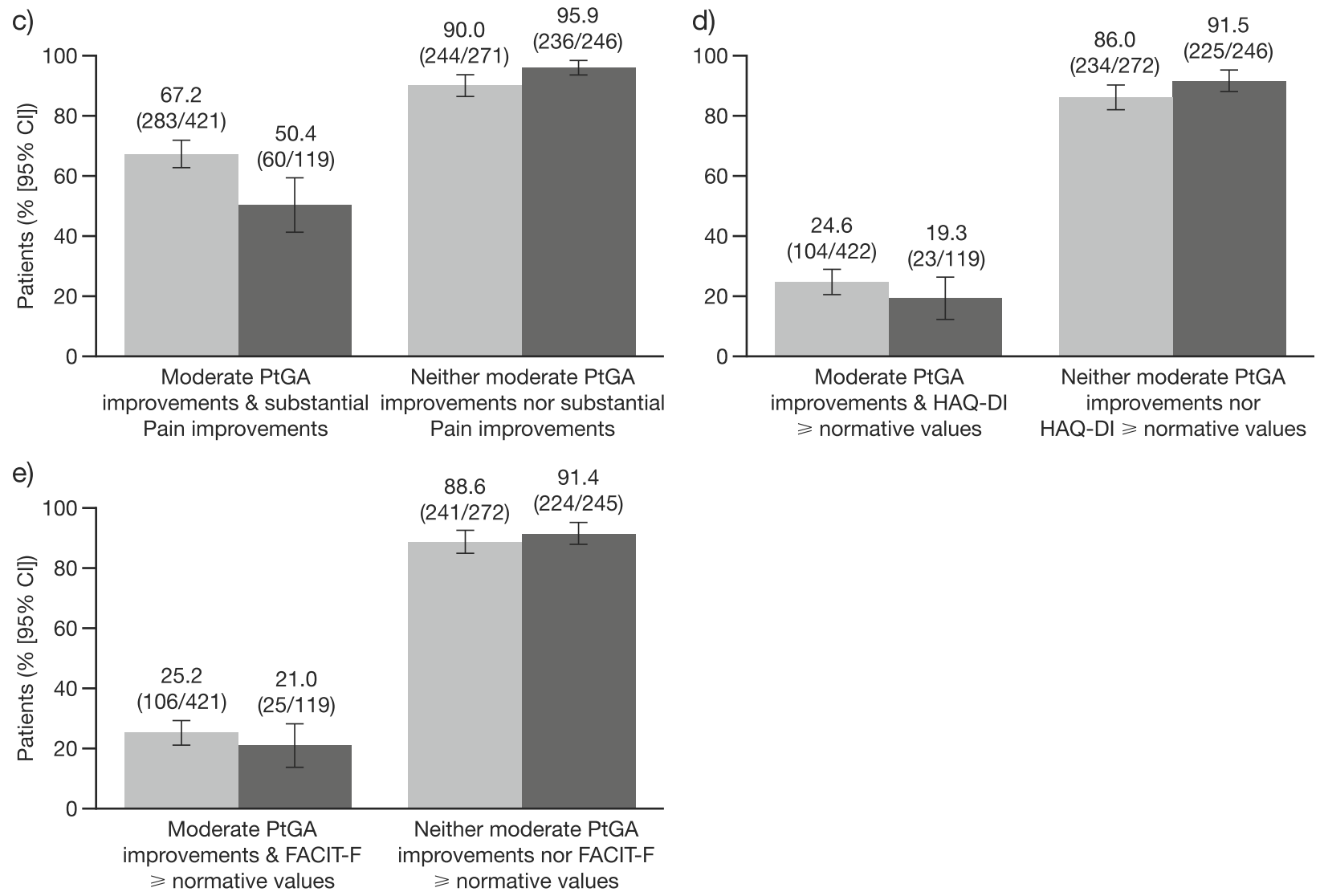

Fig. 2 Associations between moderate improvements in PtGA and Pain, HAQ-DI, and FACIT-F outcomes at month 3 in cSDMARD-IR patients. Proportions of csDMARD-IR patients at month 3 who did/did not report a mild Pain (VAS score $\leq 20 \mathrm{~mm}$ ), $\mathbf{b}$ moderate improvements in Pain ( $\geq 30 \%$ decreases from baseline), c substantial improvements in Pain ( $\geq 50 \%$ decreases from baseline), $\mathbf{d}$ HAQ-DI scores $\geq$ normative values ( $\leq 0.25$ ), or e FACIT-F scores $\geq$ normative values $(\geq 43.5$ ), stratified by reporting of moderate improvements in PtGA ( $\geq 30 \%$ decreases from baseline). Denominators represent the number of patients who did/did not report moderate PtGA improvements, respectively. Abbreviations: BID twice daily, Cl confidence interval, CSDMARD conventional synthetic disease-modifying antirheumatic drug, FACIT-F Functional Assessment of Chronic Illness Therapy-Fatigue, HAQ-DI Health Assessment Questionnaire-Disability Index, IR inadequate responder, PtGA Patient Global Assessment of Disease Activity, VAS Visual Analog Scale 


\section{Tofacitinib 5 mg BID + csDMARDs a Placebo + csDMARDs}

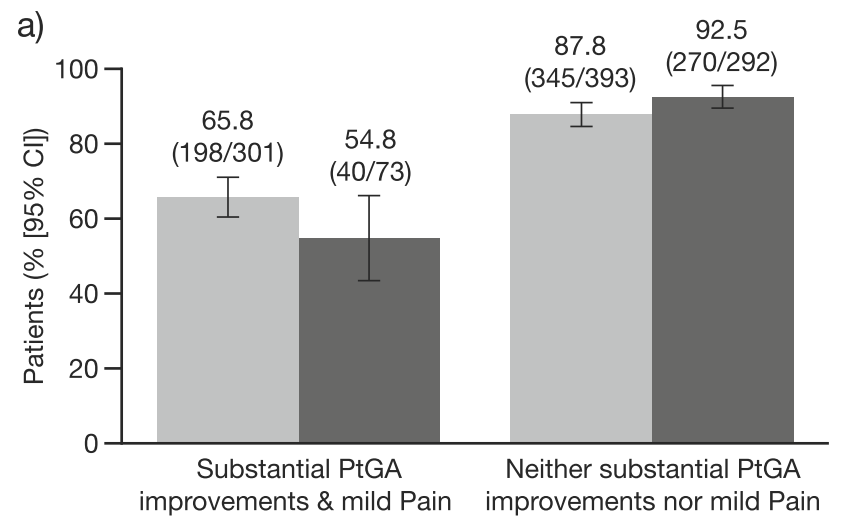

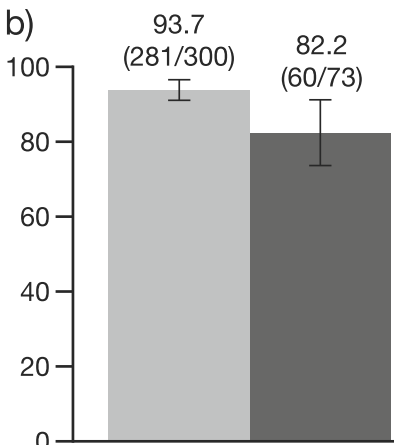

Substantial PtGA improvements \& moderate

Pain improvements
78.1 $(228 / 292)$

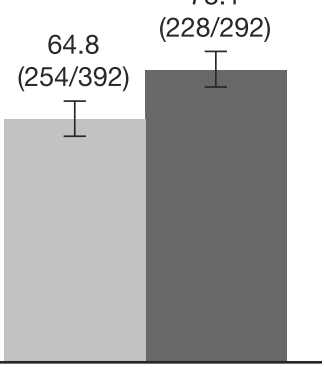

Neither substantial PtGA improvements nor moderate Pain improvements

c)

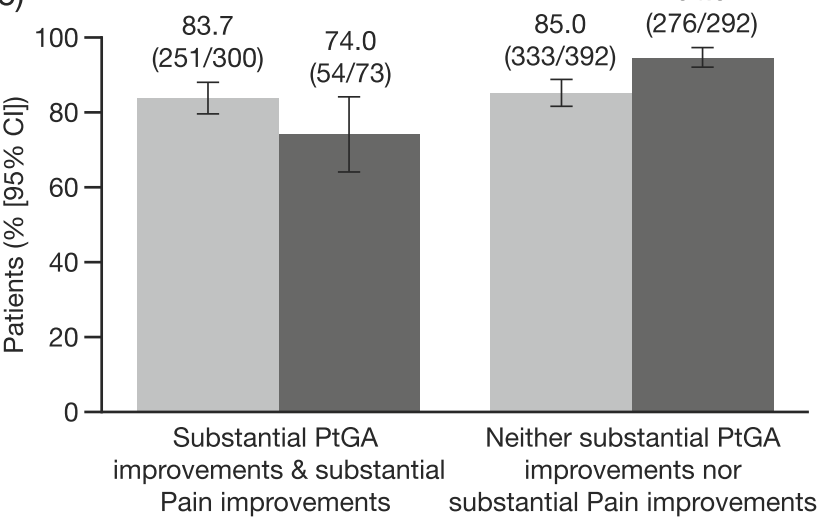

d)

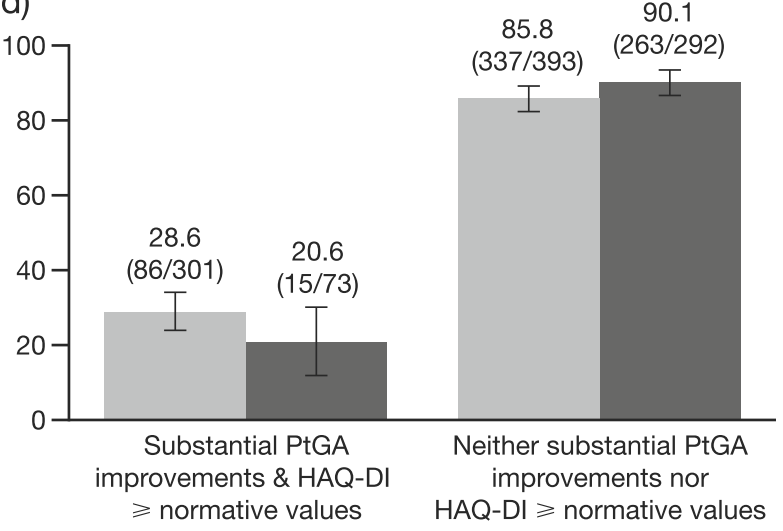

e)

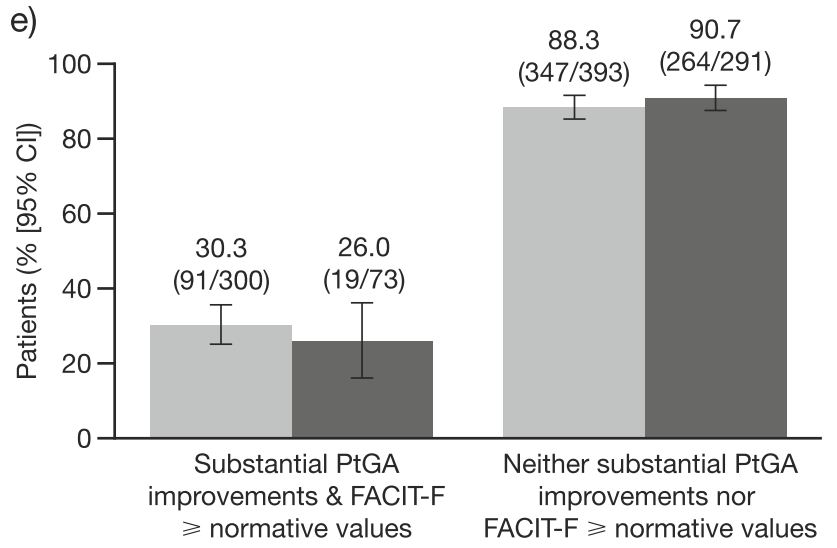

Fig. 3 Associations between substantial improvements in PtGA and Pain, HAQ-DI, and FACIT-F outcomes at month 3 in csDMARD-IR patients. Proportions of csDMARD-IR patients at month 3 who did/did not report a mild Pain (VAS score $\leq 20 \mathrm{~mm}$ ), $\mathbf{b}$ moderate improvements in Pain ( $\geq 30 \%$ decreases from baseline), $\mathbf{c}$ substantial improvements in Pain ( $\geq 50 \%$ decreases from baseline), $\mathbf{d}$ HAQ-DI scores $\geq$ normative values $(\leq 0.25)$, or e FACIT-F scores $\geq$ normative values ( $\geq 43.5)$, stratified by reporting of substantial improvements in PtGA ( $\geq 50 \%$ decreases from baseline). Denominators represent the number of patients who did/did not report substantial PtGA improvements, respectively. Abbreviations: BID twice daily, Cl confidence interval, cSDMARD conventional synthetic disease-modifying antirheumatic drug, FACIT-F Functional Assessment of Chronic Illness Therapy-Fatigue, HAQ-DI Health Assessment Questionnaire-Disability Index, IR inadequate responder, PtGA Patient Global Assessment of Disease Activity, VAS Visual Analog Scale 
showing a higher proportion of csDMARD-IR patients meeting the criteria for both PtGA and Pain/HAQ-DI/ FACIT-F outcomes versus the placebo group, and the placebo-treatment group showing a higher proportion of csDMARD-IR patients who met neither criterion versus the tofacitinib group.

Similar trends were observed in csDMARD-naïve and bDMARD-IR patients in the supporting analysis (i.e., the general order of strength of association with PtGA was pain > disability; Supplementary Figs. $7 \mathrm{a}-\mathrm{d}$ to $8 \mathrm{a}-\mathrm{d}$ [see Additional file 1]).

\section{Correlations between PtGA and pain, PtGA and HAQ-DI, and PtGA and FACIT-F}

Correlation analyses show that in general, Pain was moderately-to-strongly associated with PtGA at month 3 in csDMARD-IR patients, irrespective of treatment group (correlation coefficient generally $>0.5$ ), with the strongest correlation evident between LDA and mild Pain (Table 3). Pain was also moderately-to-strongly associated with PtGA at month 3 in csDMARD-naïve and bDMARD-IR patients (correlation coefficient generally $>0.5$; Supplementary Table 2 [see Additional file 1]).

In contrast, across both treatment arms, HAQ-DI and FACIT-F were generally weakly correlated with PtGA at month 3 in csDMARD-IR patients (correlation coefficient $<0.3$ ). In csDMARD-naïve and bDMARD-IR patients, HAQ-DI was weakly-to-moderately associated with PtGA at month 3 in tofacitinib-treated patients (correlation coefficient $>0.3$ to $<0.5$ ).

\section{Discussion}

This post hoc analysis used pooled data from csDMARD-IR RA patients enrolled in three phase 3 RCTs of tofacitinib to examine the degree to which PtGA is driven by patient-reported improvements in pain, physical function, and fatigue. This is the first such analysis to be conducted in a tofacitinib-treated population of csDMARD-IR RA patients, and, to the best of our knowledge, the first to explore the effect of tofacitinib on specific pain outcomes $(\geq 30 \%$ and $\geq 50 \%$ improvements from baseline in pain scores and attainment of mild Pain) in RA patients. The multiple clinically meaningful PRO improvements used in this study may offer an advantage over direct anchoring measures, such as the Patient Acceptable Symptom State (PASS), as they allow the evaluation of changes in PROs that may not be associated with an acceptable state of "feeling well," as defined by PASS. Furthermore, definitions of PASS are not universally accepted and may differ across patient populations.

The results of this analysis expand upon the previously reported improvements in PtGA, Pain, physical function, and fatigue in phase 3 [26-30] and phase $3 \mathrm{~b} / 4$ trials [31] of tofacitinib, by exploring and associating low symptom state attainment with the reporting of moderate and substantial clinical PRO improvements. In this analysis, clinically meaningful improvements in both PtGA and Pain ( $\geq 30 \%$ or $\geq 50 \%$ decreases from baseline), as well as the attainment of LDA (assessed by PtGA), mild Pain and improvements $\geq$ MCID in physical function (HAQ-DI) and fatigue (FACIT-F) were reported by large proportions of csDMARD-IR patients treated with tofacitinib $5 \mathrm{mg}$ BID. As expected, across all endpoints, responses were higher with active therapy versus placebo, demonstrating that treatment with tofacitinib $5 \mathrm{mg}$ BID greatly relieves the burden of disease from a patient perspective, reflecting a broad clinical benefit in RA patients. With guidelines shifting towards a more patientcentered approach to care [51], better understanding of the impact of treatment on patient-reported disease activity may help establish an improved standard for therapy assessment and modification.

The findings of our analysis indicate that PtGA responses are closely associated with Pain in csDMARDIR patients. In both tofacitinib- and placebo-treated patients, subgroup analyses from $2 \times 2$ tables showed that the reporting of mild Pain, and clinically meaningful improvements in Pain, were associated with improvements in PtGA and attainment of LDA. In addition, lack of Pain improvement was associated with little or no improvement in PtGA. Generally, across PtGA and Pain response definitions, lower proportions of patients reported either clinically meaningful improvements $(\geq 30 \%$ or $\geq 50 \%$ decreases from baseline) or a normative PtGA score (LDA) or mild Pain alone, compared with those who reported both or neither outcomes. Separate analyses of csDMARD-naïve and bDMARD-IR cohorts found generally similar associations between PtGA LDA and Pain responses.

In contrast, associations between PtGA and HAQ-DI, and PtGA and FACIT-F were less clear. When evaluating the association between PtGA and HAQ-DI, large proportions of csDMARD-IR patients reported improvements in PtGA alone, suggesting that PtGA assessments were not contingent on reporting clinically meaningful improvements in HAQ-DI scores. Separate analyses found generally similar results for HAQ-DI in csDMARD-naïve and bDMARD-IR patients. Similar trends were evident with FACIT-F scores $\geq$ normative values, again indicating that PtGA improvements were less strongly associated with fatigue. Although some trends were observed with clinically meaningful improvements in HAQ-DI and FACIT-F, large proportions of patients reported improvements $\geq$ MCID in HAQ-DI and FACIT-F or PtGA improvements alone. Thus, it is challenging to draw clear conclusions regarding the association of either HAQ-DI or FACIT-F improvements with PtGA. 
Table 3 Pearson Phi correlations between PtGA and Pain, HAQ-DI, and FACIT-F outcomes at month 3 in csDMARD-IR patients

\begin{tabular}{|c|c|c|c|}
\hline & $N$ & Correlation coefficient & $P$ value \\
\hline \multicolumn{4}{|c|}{ a) Correlation with LDA (PtGA VAS score $\leq 20 \mathrm{~mm}$ ) } \\
\hline \multicolumn{4}{|l|}{ Mild Pain (VAS score $\leq 20 \mathrm{~mm}$ ) } \\
\hline Tofacitinib 5 mg BID + csDMARDs & 695 & 0.74 & $<0.0001$ \\
\hline Placebo + csDMARDs & 366 & 0.73 & $<0.0001$ \\
\hline \multicolumn{4}{|c|}{ Moderate Pain improvement ( $\geq 30 \%$ decrease from baseline) } \\
\hline Tofacitinib 5 mg BID + csDMARDs & 692 & 0.42 & $<0.0001$ \\
\hline Placebo + csDMARDs & 365 & 0.45 & $<0.0001$ \\
\hline \multicolumn{4}{|c|}{ Substantial Pain improvement ( $\geq 50 \%$ decrease from baseline) } \\
\hline Tofacitinib 5 mg BID + csDMARDs & 692 & 0.55 & $<0.0001$ \\
\hline Placebo + csDMARDs & 365 & 0.58 & $<0.0001$ \\
\hline \multicolumn{4}{|c|}{ HAQ-DI score $\geq$ normative value $(\leq 0.25)$} \\
\hline Tofacitinib 5 mg BID + csDMARDs & 695 & 0.28 & $<0.0001$ \\
\hline Placebo + csDMARDs & 366 & 0.24 & $<0.0001$ \\
\hline \multicolumn{4}{|c|}{ HAQ-DI change $\geq$ MCID ( $\geq 0.22$ improvement from baseline) } \\
\hline Tofacitinib 5 mg BID + csDMARDs & 693 & 0.18 & $<0.0001$ \\
\hline Placebo + csDMARDs & 364 & 0.14 & 0.0064 \\
\hline \multicolumn{4}{|c|}{ FACIT-F score $\geq$ normative value $(\geq 43.5$ ) } \\
\hline Tofacitinib 5 mg BID + csDMARDs & 694 & 0.35 & $<0.0001$ \\
\hline Placebo + csDMARDs & 365 & 0.29 & $<0.0001$ \\
\hline \multicolumn{4}{|c|}{ FACIT-F change $\geq$ MCID ( $\geq 4.0$ improvement from baseline) } \\
\hline Tofacitinib 5 mg BID + csDMARDs & 693 & 0.13 & 0.0004 \\
\hline Placebo + csDMARDs & 363 & 0.11 & 0.0413 \\
\hline
\end{tabular}

b) Correlation with moderate PtGA improvement ( $\geq 30 \%$ decrease from baseline)

Mild Pain (VAS score $\leq \mathbf{2 0} \mathrm{mm}$ )

Tofacitinib 5 mg BID + csDMARDs 694

Placebo + csDMARDs

Moderate Pain improvement ( $\geq 30 \%$ decrease from baseline)

Tofacitinib 5 mg BID + csDMARDs

692

Placebo + csDMARDs

365

Substantial Pain improvement ( $\geq 50 \%$ decrease from baseline)

Tofacitinib 5 mg BID + csDMARDs

Placebo + csDMARDs

HAQ-DI score $\geq$ normative value $(\leq \mathbf{0 . 2 5})$

Tofacitinib 5 mg BID + csDMARDs

Placebo + csDMARDs

HAQ-DI change $\geq$ MCID ( $\geq 0.22$ improvement from baseline)

Tofacitinib 5 mg BID + csDMARDs

Placebo + csDMARDs

FACIT-F score $\geq$ normative value $(\geq 43.5$ )

Tofacitinib 5 mg BID + csDMARDs

Placebo + csDMARDs 
Table 3 Pearson Phi correlations between PtGA and Pain, HAQ-DI, and FACIT-F outcomes at month 3 in csDMARD-IR patients (Continued)

\begin{tabular}{|c|c|c|c|}
\hline & $N$ & Correlation coefficient & $P$ value \\
\hline \multicolumn{4}{|c|}{ FACIT-F change $\geq$ MCID ( $\geq 4.0$ improvement from baseline) } \\
\hline Tofacitinib 5 mg BID + csDMARDs & 692 & 0.24 & $<0.0001$ \\
\hline Placebo + csDMARDs & 363 & 0.26 & $<0.0001$ \\
\hline \multicolumn{4}{|c|}{$\begin{array}{l}\text { c) Correlation with substantial PtGA improvement } \\
\text { ( } \geq 50 \% \text { decrease from baseline) }\end{array}$} \\
\hline \multicolumn{4}{|l|}{ Mild Pain (VAS score $\leq 20 \mathrm{~mm}$ ) } \\
\hline Tofacitinib 5 mg BID + csDMARDs & 694 & 0.55 & $<0.0001$ \\
\hline Placebo + csDMARDs & 365 & 0.50 & $<0.0001$ \\
\hline \multicolumn{4}{|c|}{ Moderate Pain improvement ( $\geq 30 \%$ decrease from baseline) } \\
\hline Tofacitinib 5 mg BID + csDMARDs & 692 & 0.59 & $<0.0001$ \\
\hline Placebo + csDMARDs & 365 & 0.51 & $<0.0001$ \\
\hline \multicolumn{4}{|c|}{ Substantial Pain improvement ( $\geq 50 \%$ decrease from baseline) } \\
\hline Tofacitinib 5 mg BID + csDMARDs & 692 & 0.68 & $<0.0001$ \\
\hline Placebo + csDMARDs & 365 & 0.70 & $<0.0001$ \\
\hline \multicolumn{4}{|c|}{ HAQ-DI score $\geq$ normative value $(\leq 0.25)$} \\
\hline Tofacitinib 5 mg BID + csDMARDs & 694 & 0.18 & $<0.0001$ \\
\hline Placebo + csDMARDs & 365 & 0.13 & 0.0126 \\
\hline \multicolumn{4}{|c|}{ HAQ-DI change $\geq$ MCID ( $\geq 0.22$ improvement from baseline) } \\
\hline Tofacitinib 5 mg BID + csDMARDs & 692 & 0.29 & $<0.0001$ \\
\hline Placebo + csDMARDs & 364 & 0.26 & $<0.0001$ \\
\hline \multicolumn{4}{|c|}{ FACIT-F score $\geq$ normative value $(\geq 43.5$ ) } \\
\hline Tofacitinib 5 mg BID + csDMARDs & 693 & 0.23 & $<0.0001$ \\
\hline Placebo + csDMARDs & 364 & 0.20 & 0.0001 \\
\hline \multicolumn{4}{|c|}{ FACIT-F change $\geq$ MCID ( $\geq 4.0$ improvement from baseline) } \\
\hline Tofacitinib 5 mg BID + csDMARDs & 692 & 0.26 & $<0.0001$ \\
\hline Placebo + csDMARDs & 363 & 0.23 & $<0.0001$ \\
\hline
\end{tabular}

Generally, correlation coefficient values around $0.3,0.5$, and 0.7 are considered as weak, moderate, and strong positive linear correlations, respectively Abbreviations: BID twice daily, csDMARD conventional synthetic disease-modifying antirheumatic drug, FACIT-F Functional Assessment of Chronic Illness TherapyFatigue, HAQ-DI Health Assessment Questionnaire-Disability Index, IR inadequate responder, LDA low disease activity, MCID minimum clinically important difference, PtGA Patient Global Assessment of Disease Activity, VAS Visual Analog Scale

The greater associations observed between PtGA and Pain, compared with the other PROs were further supported by correlation analyses. Pearson Phi correlation coefficients at month 3 indicated a stronger association between PtGA and Pain than between PtGA and HAQ-DI or FACIT-F (either improvements $\geq$ MCID or scores $\geq$ normative values) in csDMARD-IR patients in the main analysis. In the supporting analysis, a stronger association between PtGA and Pain than between PtGA and HAQ-DI (scores $\geq$ normative values) was observed in csDMARDnaïve and bDMARD-IR patients. In line with previous evidence from other RA trials, these results indicate that Pain is the key driver of PtGA [9, 12-15]; while physical function and fatigue influence PtGA to a lesser extent $[12,14]$. The results of this analysis are further corroborated by the findings of an international survey of 1958 RA patients, in which patients most frequently defined a "good day" as a day free of pain; interestingly, the majority of patients also characterized a "good day" as being free of fatigue, and, to a lesser extent, the ability to engage in all activities [52]. These observations support existing evidence that pain alleviation is particularly important to RA patients and that sensitivity and attention to pain are crucial in meeting patients' expectations of their arthritis care $[12,52]$. A previous study has shown that pain remains a primary priority for patients, regardless of overall improvements in health status following treatment [53]. Moreover, pain is the most common symptom experienced by RA patients [54] and is the primary reason why patients with inflammatory arthritis see a rheumatologist [15].

The importance of adequately addressing patients' pain levels in parallel with monitoring broader disease activity is further emphasized by the fact that pain has been shown to persist in RA patients who had Disease 
Activity Score in 28 joints, CRP (DAS28-4[CRP]) $<2.6$ for over 1 year [55]. In the same study, CRP, SJC, TJC, and Sharp scores were not found to be significantly associated with increased pain severity at baseline or 1 year, indicating a non-inflammatory pain component is at play [55]. This hypothesis is further supported by a recently published study, which reported that a substantial proportion of RA patients reported unacceptable pain levels despite inflammation control following 2 years of early active treatment (begun < 1 year following RA onset) [56]. It has been proposed that increased sensitivity and presence of non-inflammatory pain in RA patients is due to central nervous system alterations in pain processing $[57,58]$. In line with this theory, decreased pain thresholds in RA patients have been reported in both inflamed joints and tissues unaffected by inflammation [57, 58]. These findings further emphasize the importance of regular assessment of PROs, particularly those which evaluate pain. Without these, disease activity goals such as remission per composite measures may be achieved, yet patients whose pain is not adequately monitored/ controlled are significantly more likely to report that their treatment expectations remain unmet [59].

A 2015 analysis of PROs in practice reported that clinicians are often reluctant to use PROs routinely due to a fear that it will add to their workload, rather than improve their efficiency and effectiveness [60]; therefore, it is important that incorporation of PROs into clinical practice not be burdensome [61]. PtGA is a single question that takes little time to ask and requires no training to interpret, making it a feasible, efficient measure of disease activity in the clinical setting [62]. However, while the results of this analysis indicate that, captured alone, PtGA correlates strongly with Pain, the weak correlations seen between PtGA and HAQ-DI/FACIT-F demonstrate that it provides little insight into patients' physical function or levels of fatigue. In contrast, RAPID-3 (Routine Assessment of Patient Index Data 3), a pooled index of PtGA, Pain, and HAQ-DI that equally weights all three components [63], is a quick and easy method to obtain a comprehensive overview of patient wellbeing that has been shown to correlate strongly with clinical measures of disease activity, such as DAS28-4, erythrocyte sedimentation rate and Clinical Disease Activity Index [64, 65]. Given prior research and our current findings, clinicians using RAPID-3 may also consider collecting a single additional measure, fatigue (e.g., FACIT-F or fatigue VAS), to gain a more robust picture of patient state in a time-pressured clinical setting.

Some limitations remain associated with this post hoc analysis. First, as placebo-treated patients were advanced to tofacitinib treatment at month 3 (non-responders only) or month 6 (all remaining placebo-treated patients), data in this post hoc analysis were only evaluated up to month 3 , a relatively short period to adequately investigate the associations. In addition, interpretations of PtGA by patients will vary and depend on a range of additional factors, such as comorbidities, disease duration, and patient expectations [9]. Furthermore, as PtGA asks patients to assess their disease activity based on "all the ways your disease affects you," their scoring is based on other impacts of disease that may not be queried by pain, physical function, or fatigue. There may also have been an impact of unmeasured, non-RA factors such as demographic characteristics, education level, and cultural or geographical influences on patient assessments and perceptions of disease activity and burden. Moreover, painful comorbid conditions not impacted by treatment with tofacitinib or csDMARDs may have influenced the pain scores recorded by study patients. However, it is plausible that any such effect would have been similar between groups due to the randomized trial design. While the Pearson Phi correlation coefficients are useful for measuring linear relationships, the correlation analysis conducted was exploratory in nature; therefore, results should be interpreted with caution. There is a potential bias in this analysis as the assessments of PtGA and pain were based on similar measurement scales (VAS). However, we are not aware of any literature that has established that PRO associations are solely or predominantly based on using the same measurement scale. Prior work has shown that pain is a major determinant of PtGA in RA, but this was not due to the measurement scales used (VAS or numerical rating scale) [9]. The current analysis found not only a similar association between improvements in Pain and PtGA, but also one (albeit weaker) between HAQ-DI and PtGA, despite HAQ-DI data being collected using different questions. As previously noted, prior research has found occasional discordance between PtGA and MDGA in patients with RA $[12,13,17,19]$, even when those outcomes were collected via similar scales [17]. Finally, patient numbers in the cSDMARD-naïve and bDMARD-IR cohorts were low, compared with the csDMARD-IR cohort, and further study will be required to confirm the results of this analysis in these patient populations.

\section{Conclusions}

For the first time, this post hoc analysis of pooled data from three phase 3 RCTs of csDMARD-IR RA patients demonstrates the associations between PtGA and pain, physical function, and fatigue in tofacitinib-treated patients, corroborating the importance of clinically meaningful improvements in PROs and attainment of LDA states for the optimization of patient care. Similar findings were generally seen in csDMARD-naïve and bDMARD-IR patients. Overall, the findings support the importance of PtGA in clinical practice, and the role of Pain, and, to a lesser extent, physical function and fatigue, in driving patients' perceptions of disease activity. 
While PtGA remains one of the most widely reported PROs, RAPID-3 represents a time-efficient approach that collects three outcomes (PtGA, Pain, and HAQ-DI) and may be supplemented by the addition of a single fatigue measure to provide a more robust picture of patient wellbeing.

\section{Supplementary information}

Supplementary information accompanies this paper at https://doi.org/10. 1186/s13075-020-02324-7.

\section{Additional file 1: Supplementary Tables 1-2; Supplementary}

Figures 1-8. Proportions of patients who did/did not report improvements in HAQ-DI and FACIT-F scores $\geq$ MCID, stratified by clinically meaningful PtGA improvements; proportions of patients who reported clinically meaningful PtGA improvements or clinically meaningful Pain, HAQ-DI, or FACIT-F improvements alone; and Pearson Phi correlations between PtGA, and Pain and HAQ-DI outcomes.

\begin{abstract}
Abbreviations
ACR: American College of Rheumatology; bDMARD: Biologic diseasemodifying antirheumatic drug; BID: Twice daily; Cl: Confidence interval; CRP: C-reactive protein; csDMARD: Conventional synthetic disease-modifying antirheumatic drug; DAS28-4: Disease Activity Score in 28 joints; ESR: Erythrocyte sedimentation rate; EULAR: European League Against Rheumatism; FACIT-F: Functional Assessment of Chronic Illness TherapyFatigue; HAQ-DI: Health Assessment Questionnaire-Disability Index; HRQoL: Health-related quality of life; IR: Inadequate responder; LDA: Low disease activity; LTE: Long-term extension; MCID: Minimum clinically important difference; MDGA: Physician Global Assessment of Arthritis; MR: Modified-release; MTX: Methotrexate; OMERACT: Outcome Measures in Rheumatology; PASS: Patient Acceptable Symptom State; PRO: Patientreported outcome; PtGA: Patient Global Assessment of Disease Activity; QD: Once daily; RA: Rheumatoid arthritis; RAPID-3: Routine Assessment of Patient Index Data 3; RCT: Randomized controlled trial; RF: Rheumatoid factor; SD: Standard deviation; SF-36: 36-Item Short Form Health Survey; SJC: Swollen joint count; TJC: Tender joint count; VAS: Visual Analog Scale
\end{abstract}

\section{Acknowledgements}

The authors would like to thank the study patients and investigators. Medical writing support under the guidance of the authors was provided by Kirsten Woollcott, MSc, CMC Connect, McCann Health Medical Communications, and was funded by Pfizer Inc, New York, NY, USA, in accordance with Good Publication Practice (GPP3) guidelines (Ann Intern Med 2015;163:461-464).

\section{Authors' contributions}

All authors were involved in the analysis and interpretation of data and in critically revising the manuscript for important intellectual content. All authors agree to be accountable for all aspects of the work and read and approved the final manuscript to be published.

\section{Funding}

This work was sponsored by Pfizer Inc. Pfizer authors participated in study design, analysis, and interpretation of the data, and the writing of the manuscript.

\section{Availability of data and materials}

Upon request, and subject to certain criteria, conditions, and exceptions, see (https://www.pfizer.com/science/clinical-trials/trial-data-and-results for more information), Pfizer will provide access to individual de-identified participant data from Pfizer-sponsored global interventional clinical studies conducted for medicines, vaccines, and medical devices (1) for indications that have been approved in the USA and/or EU or (2) in programs that have been terminated (i.e., development for all indications has been discontinued). Pfizer will also consider requests for the protocol, data dictionary, and statistical analysis plan. Data may be requested from Pfizer trials 24 months after study completion. The de-identified participant data will be made available to researchers whose proposals meet the research criteria and other conditions, and for which an exception does not apply, via a secure portal. To gain access, data requestors must enter into a data access agreement with Pfizer.

\section{Ethics approval and consent to participate}

Each randomized controlled trial was conducted in accordance with the Declaration of Helsinki and International Conference on Harmonization Guidelines for Good Clinical Practice and was approved by the institutional review board and/or independent ethics committee for each study center. All patients provided written informed consent.

\section{Consent for publication}

Not applicable.

\section{Competing interests}

VS has received consulting fees or other remuneration from AbbVie, Amgen, Bristol-Myers Squibb, Corrona, Eli Lilly, Janssen, Novartis, Pfizer Inc, and UCB. JK has participated in speakers' bureaus and has consulted for Pfizer Inc. RA has received research grants and speakers' honoraria from Pfizer Inc. GW was an employee and shareholder of Pfizer Inc at the time of the analysis.

$A D, H S, R G$, and CWM are employees of Pfizer Inc and own stock or stock options in Pfizer Inc

\section{Author details}

${ }^{1}$ Division of Immunology/Rheumatology, Stanford University, Palo Alto, CA, USA. ${ }^{2}$ Independent Healthcare Associates Inc, Cullowhee, NC, USA.

${ }^{3}$ Schlosspark-Klinik, University Medicine, Berlin, Germany. ${ }^{4}$ Pfizer Inc, Groton, CT, USA. ${ }^{5}$ Pfizer Inc, Collegeville, PA, USA. ${ }^{6}$ Pfizer Inc, New York, NY, USA.

Received: 5 November 2019 Accepted: 22 September 2020

Published online: 15 October 2020

\section{References}

1. Strand V, Singh JA. Newer biological agents in rheumatoid arthritis: impact on health-related quality of life and productivity. Drugs. 2010;70:121-45.

2. Carr A, Hewlett S, Hughes R, Mitchell H, Ryan S, Carr M, et al. Rheumatology outcomes: the patient's perspective. J Rheumatol. 2003:30:880-3.

3. Kirwan JR, Hewlett SE, Heiberg T, Hughes RA, Carr M, Hehir M, et al. Incorporating the patient perspective into outcome assessment in rheumatoid arthritis--progress at OMERACT 7. J Rheumatol. 2005;32:2250-6.

4. Kirwan JR, Tugwell PS. Overview of the patient perspective at OMERACT 10--conceptualizing methods for developing patient-reported outcomes. J Rheumatol. 2011;38:1699-701.

5. Felson DT, Anderson JJ, Boers M, Bombardier C, Chernoff M, Fried B, et al. The American College of Rheumatology preliminary core set of disease activity measures for rheumatoid arthritis clinical trials. The Committee on Outcome Measures in Rheumatoid Arthritis Clinical Trials. Arthritis Rheum. 1993:36:729-40.

6. Gossec L, Paternotte S, Aanerud GJ, Balanescu A, Boumpas DT, Carmona L, et al. Finalisation and validation of the rheumatoid arthritis impact of disease score, a patient-derived composite measure of impact of rheumatoid arthritis: a EULAR initiative. Ann Rheum Dis. 2011;70:935-42.

7. US Food and Drug Administration. Guidance for Industry. Patient-reported outcome measures: use in medical product development to support labeling claims 2009. https://www.fda.gov/downloads/drugs/guidances/ ucm193282.pdf. Accessed 25 Sept 2020

8. Kvitkina T, ten Haaf A, Reken S, McGauran N, Wieseler B. Patient-relevant outcomes and surrogates in the early benefit assessment of drugs: first experiences. Z Evid Fortbild Qual Gesundhwes. 2014;108:528-38.

9. Nikiphorou E, Radner H, Chatzidionysiou K, Desthieux C, Zabalan C, van EijkHustings $Y$, et al. Patient global assessment in measuring disease activity in rheumatoid arthritis: a review of the literature. Arthritis Res Ther. 2016;18:251.

10. Ward MM. Clinical measures in rheumatoid arthritis: which are most useful in assessing patients? J Rheumatol. 1994;21:17-27.

11. Kirwan JR, Minnock P, Adebajo A, Bresnihan B, Choy E, de Wit M, et al. Patient perspective: fatigue as a recommended patient centered outcome measure in rheumatoid arthritis. J Rheumatol. 2007;34:1174-7.

12. Khan NA, Spencer HJ, Abda E, Aggarwal A, Alten R, Ancuta C, et al. Determinants of discordance in patients' and physicians' rating of rheumatoid arthritis disease activity. Arthritis Care Res (Hoboken). 2012;64: 206-14. 
13. Studenic P, Radner H, Smolen JS, Aletaha D. Discrepancies between patients and physicians in their perceptions of rheumatoid arthritis disease activity. Arthritis Rheum. 2012;64:2814-23.

14. Desthieux C, Hermet A, Granger B, Fautrel B, Gossec L. Patient-physician discordance in global assessment in rheumatoid arthritis: a systematic literature review with metaanalysis. Arthritis Care Res (Hoboken). 2016;68: 1767-73.

15. Lee YC. Effect and treatment of chronic pain in inflammatory arthritis. Curr Rheumatol Rep. 2013;15:300.

16. Barton JL, Imboden J, Graf J, Glidden D, Yelin EH, Schillinger D. Patientphysician discordance in assessments of global disease severity in rheumatoid arthritis. Arthritis Care Res (Hoboken). 2010;62:857-64.

17. Karpouzas GA, Ramadan SN, Cost CE, Draper TL, Hernandez E, Strand V, et al. Discordant patient-physician assessments of disease activity and its persistence adversely impact quality of life and work productivity in US Hispanics with rheumatoid arthritis. RMD Open. 2017;3:e000551.

18. Karpouzas GA, Strand V, Ormseth SR. Latent profile analysis approach to the relationship between patient and physician global assessments of rheumatoid arthritis activity. RMD Open. 2018;4:e000695.

19. Smolen JS, Strand V, Koenig AS, Szumski A, Kotak S, Jones TV. Discordance between patient and physician assessments of global disease activity in rheumatoid arthritis and association with work productivity. Arthritis Res Ther. 2016;18:114.

20. Busch-Dienstfertig M, González-Rodríguez S. IL-4, JAK-STAT signaling, and pain. JAKSTAT. 2013;2:e27638.

21. Salaffi F, Giacobazzi G, Di Carlo M. Chronic pain in inflammatory arthritis: mechanisms, metrology, and emerging targets-a focus on the JAK-STAT pathway. Pain Res Manag. 2018;2018:8564215

22. Banerjee S, Biehl A, Gadina M, Hasni S, Schwartz DM. JAK-STAT signaling as a target for inflammatory and autoimmune diseases: current and future prospects. Drugs. 2017;77:521-46.

23. Xin P, Xu X, Deng C, Liu S, Wang Y, Zhou X, et al. The role of JAK/STAT signaling pathway and its inhibitors in diseases. Int Immunopharmacol. 2020;80:106210.

24. Ogdie A, de Vlam K, McInnes IB, Mease PJ, Baer P, Lukic T, et al. Efficacy of tofacitinib in reducing pain in patients with rheumatoid arthritis, psoriatic arthritis or ankylosing spondylitis. RMD Open. 2020;6:e001042.

25. Wallenstein GV, Kanik KS, Wilkinson B, Cohen S, Cutolo M, Fleishmann R, et al. Effects of the oral Janus kinase inhibitor tofacitinib on patient-reported outcomes in patients with active rheumatoid arthritis: results of two phase 2 randomised controlled trials. Clin Exp Rheumatol. 2016;34:430-42.

26. Strand V, Kremer J, Wallenstein G, Kanik KS, Connell C, Gruben D, et al. Effects of tofacitinib monotherapy on patient-reported outcomes in a randomized phase 3 study of patients with active rheumatoid arthritis and inadequate responses to DMARDs. Arthritis Res Ther. 2015;17:307.

27. Strand V, van Vollenhoven RF, Lee EB, Fleischmann R, Zwillich SH, Gruben D, et al. Tofacitinib or adalimumab versus placebo: patient-reported outcomes from a phase 3 study of active rheumatoid arthritis. Rheumatology (Oxford). 2016;55:1031-41.

28. Strand V, Lee EB, Fleischmann R, Alten RE, Koncz T, Zwillich SH, et al. Tofacitinib versus methotrexate in rheumatoid arthritis: patient-reported outcomes from the randomised phase III ORAL Start trial. RMD Open. 2016;2:e000308.

29. Strand V, Kremer JM, Gruben D, Krishnaswami S, Zwillich SH, Wallenstein GV. Tofacitinib in combination with conventional disease-modifying antirheumatic drugs in patients with active rheumatoid arthritis: patientreported outcomes from a Phase III randomized controlled trial. Arthritis Care Res (Hoboken). 2017;69:592-8.

30. Strand V, Burmester GR, Zerbini CA, Mebus CA, Zwillich SH, Gruben D, et al. Tofacitinib with methotrexate in third-line treatment of patients with active rheumatoid arthritis: patient-reported outcomes from a phase III trial. Arthritis Care Res. 2015;67:475-83.

31. Strand V, Mysler E, Moots RJ, Wallenstein G, DeMasi R, Gruben D, et al. Patient-reported outcomes for tofacitinib with and without methotrexate, or adalimumab with methotrexate, in rheumatoid arthritis: a phase IIIB/IV trial. RMD Open. 2019:5:e001040.

32. Wollenhaupt J, Silverfield J, Lee EB, Curtis JR, Wood SP, Soma K, et al. Safety and efficacy of tofacitinib, an oral Janus kinase inhibitor, for the treatment of rheumatoid arthritis in open-label, longterm extension studies. J Rheumatol. 2014;41:837-52.

33. Yamanaka H, Tanaka Y, Takeuchi T, Sugiyama N, Yuasa $H$, Toyoizumi S, et al. Tofacitinib, an oral Janus kinase inhibitor, as monotherapy or with background methotrexate, in Japanese patients with rheumatoid arthritis: an open-label, long-term extension study. Arthritis Res Ther. 2016;18:34.

34. Wollenhaupt J, Lee EB, Curtis JR, Silverfield J, Terry K, Soma K, et al. Safety and efficacy of tofacitinib for up to 9.5 years in the treatment of rheumatoid arthritis: final results of a global, open-label, long-term extension study. Arthritis Res Ther. 2019;21:89.

35. Kremer J, Li Z-G, Hall S, Fleischmann R, Genovese M, Martin-Mola E, et al. Tofacitinib in combination with nonbiologic disease-modifying antirheumatic drugs in patients with active rheumatoid arthritis: a randomized trial. Ann Intern Med. 2013;159:253-61.

36. van Vollenhoven RF, Fleischmann R, Cohen S, Lee EB, García Meijide JA, Wagner $\mathrm{S}$, et al. Tofacitinib or adalimumab versus placebo in rheumatoid arthritis. N Engl J Med. 2012;367:508-19.

37. van der Heijde D, Tanaka Y, Fleischmann R, Keystone E, Kremer J, Zerbini C, et al. Tofacitinib $(C P-690,550)$ in patients with rheumatoid arthritis receiving methotrexate: twelve-month data from a twenty-four-month phase III randomized radiographic study. Arthritis Rheum. 2013:65:559-70.

38. Strand V, van der Heijde D, Tanaka Y, Keystone E, Kremer J, Zerbini CAF, et al. Tofacitinib in combination with methotrexate in patients with rheumatoid arthritis: patient-reported outcomes from the 24-month Phase 3 ORAL Scan study. Clin Exp Rheumatol. 2020;38:848-57.

39. Arnett FC, Edworthy SM, Bloch DA, McShane DJ, Fries JF, Cooper NS, et al. The American Rheumatism Association 1987 revised criteria for the classification of rheumatoid arthritis. Arthritis Rheum. 1988;31:315-24.

40. Lee EB, Fleischmann R, Hall S, Wilkinson B, Bradley J, Gruben D, et al. Tofacitinib versus methotrexate in rheumatoid arthritis. N Engl J Med. 2014; 370:2377-86.

41. Burmester GR, Blanco R, Charles-Schoeman C, Wollenhaupt J, Zerbini C, Benda B, et al. Tofacitinib (CP-690,550) in combination with methotrexate in patients with active rheumatoid arthritis with an inadequate response to tumour necrosis factor inhibitors: a randomised phase 3 trial. Lancet. 2013; 381:451-60.

42. Wells GA, Boers M, Shea B, Brooks PM, Simon LS, Strand CV, et al. Minimal disease activity for rheumatoid arthritis: a preliminary definition. J Rheumatol. 2005;32:2016-24.

43. Strand V, Boers M, Idzerda L, Kirwan JR, Kvien TK, Tugwell PS, et al. It's good to feel better but it's better to feel good and even better to feel good as soon as possible for as long as possible. Response criteria and the importance of change at OMERACT 10. J Rheumatol. 2011;38:1720-7.

44. Dworkin RH, Turk DC, Wyrwich KW, Beaton D, Cleeland CS, Farrar JT, et al. Interpreting the clinical importance of treatment outcomes in chronic pain clinical trials: IMMPACT recommendations. J Pain. 2008;9:105-21.

45. Farrar JT, Young JP Jr, LaMoreaux L, Werth JL, Poole RM. Clinical importance of changes in chronic pain intensity measured on an 11-point numerical pain rating scale. Pain. 2001;94:149-58.

46. Krishnan E, Sokka T, Häkkinen A, Hubert H, Hannonen P. Normative values for the Health Assessment Questionnaire disability index: benchmarking disability in the general population. Arthritis Rheum. 2004;50:953-60.

47. Wells GA, Tugwell P, Kraag GR, Baker PR, Groh J, Redelmeier DA. Minimum important difference between patients with rheumatoid arthritis: the patient's perspective. J Rheumatol. 1993;20:557-60.

48. Montan I, Löwe B, Cella D, Mehnert A, Hinz A. General population norms for the Functional Assessment of Chronic Illness Therapy (FACIT)-Fatigue scale. Value Health. 2018;21:1313-21.

49. Cella D, Lai JS, Chang CH, Peterman A, Slavin M. Fatigue in cancer patients compared with fatigue in the general United States population. Cancer. 2002;94:528-38.

50. Cella D, Yount S, Sorensen M, Chartash E, Sengupta N, Grober J. Validation of the Functional Assessment of Chronic Illness Therapy Fatigue Scale relative to other instrumentation in patients with rheumatoid arthritis. J Rheumatol. 2005;32:811-9.

51. Stoffer MA, Smolen JS, Woolf A, Ambrozic A, Bosworth A, Carmona L, et al. Development of patient-centred standards of care for rheumatoid arthritis in Europe: the eumusc.net project. Ann Rheum Dis. 2014;73:902-5.

52. Strand V, Wright GC, Bergman MJ, Tambiah J, Taylor PC. Patient expectations and perceptions of goal-setting strategies for disease management in rheumatoid arthritis. J Rheumatol. 2015;42:2046-54.

53. ten Klooster PM, Veehof MM, Taal E, van Riel PL, van de Laar MA. Changes in priorities for improvement in patients with rheumatoid arthritis during 1 year of anti-tumour necrosis factor treatment. Ann Rheum Dis. 2007;66: 1485-90. 
54. American College of Rheumatology Pain Management Task Force. Report of the American College of Rheumatology Pain Management Task Force. Arthritis Care Res (Hoboken). 2010;62:590-9.

55. Lee YC, Cui J, Lu B, Frits ML, lannaccone CK, Shadick NA, et al. Pain persists in DAS28 rheumatoid arthritis remission but not in ACR/EULAR remission: a longitudinal observational study. Arthritis Res Ther. 2011;13:R83.

56. Olofsson T, Wallman JK, Jöud A, Schelin ME, Ernestam $\mathrm{S}$, van Vollenhoven R, et al. Unacceptable, refractory pain despite inflammation control in early rheumatoid arthritis and its relation to treatment strategy: results from the randomised controlled SWEFOT trial. Ann Rheum Dis. 2018;77(Suppl 2):117 OP0133.

57. Edwards RR, Wasan AD, Bingham CO 3rd, Bathon J, Haythornthwaite JA, Smith MT, et al. Enhanced reactivity to pain in patients with rheumatoid arthritis. Arthritis Res Ther. 2009;11:R61.

58. Leffler AS, Kosek E, Lerndal T, Nordmark B, Hansson P. Somatosensory perception and function of diffuse noxious inhibitory controls (DNIC) in patients suffering from rheumatoid arthritis. Eur J Pain. 2002;6:161-76.

59. Rao JK, Weinberger M, Anderson LA, Kroenke K. Predicting reports of unmet expectations among rheumatology patients. Arthritis Rheum. 2004;51:215-21.

60. Nelson EC, Eftimovska E, Lind C, Hager A, Wasson JH, Lindblad S. Patient reported outcome measures in practice. BMJ. 2015;350:g7818.

61. Fautrel B, Alten R, Kirkham B, de la Torre I, Durand F, Barry J, et al. Call for action: how to improve use of patient-reported outcomes to guide clinical decision making in rheumatoid arthritis. Rheumatol Int. 2018;38:935-47.

62. Anderson JK, Zimmerman L, Caplan L, Michaud K. Measures of rheumatoid arthritis disease activity: Patient (PtGA) and Provider (PrGA) Global Assessment of Disease Activity, Disease Activity Score (DAS) and Disease Activity Score with 28-Joint Counts (DAS28), Simplified Disease Activity Index (SDAI), Clinical Disease Activity Index (CDAl), Patient Activity Score (PAS) and Patient Activity Score-II (PASII), Routine Assessment of Patient Index Data (RAPID), Rheumatoid Arthritis Disease Activity Index (RADAl) and Rheumatoid Arthritis Disease Activity Index-5 (RADAl-5), Chronic Arthritis Systemic Index (CASI), Patient-Based Disease Activity Score With ESR (PDAS1) and Patient-Based Disease Activity Score without ESR (PDAS2), and Mean Overall Index for Rheumatoid Arthritis (MOI-RA). Arthritis Care Res (Hoboken). 2011;63 Suppl 11:S14-S36.

63. Pincus T, Furer V, Keystone E, Yazici Y, Bergman MJ, Luijtens K. RAPID3 (Routine Assessment of Patient Index Data 3) severity categories and response criteria: Similar results to DAS28 (Disease Activity Score) and CDAl (Clinical Disease Activity Index) in the RAPID 1 (Rheumatoid Arthritis Prevention of Structural Damage) clinical trial of certolizumab pegol. Arthritis Care Res (Hoboken). 2011;63:1142-9.

64. Pincus T, Swearingen CJ, Bergman MJ, Colglazier CL, Kaell AT, Kunath AM, et al. RAPID3 (Routine Assessment of Patient Index Data) on an MDHAQ (Multidimensional Health Assessment Questionnaire): agreement with DAS28 (Disease Activity Score) and CDAl (Clinical Disease Activity Index) activity categories, scored in five versus more than ninety seconds. Arthritis Care Res (Hoboken). 2010;62:181-9.

65. Pincus T, Swearingen CJ, Bergman M, Yazici Y. RAPID3 (Routine Assessment of Patient Index Data 3), a rheumatoid arthritis index without formal joint counts for routine care: proposed severity categories compared to disease activity score and clinical disease activity index categories. J Rheumatol. 2008:35:2136-47.

\section{Publisher's Note}

Springer Nature remains neutral with regard to jurisdictional claims in published maps and institutional affiliations.

Ready to submit your research? Choose BMC and benefit from:
- fast, convenient online submission
- thorough peer review by experienced researchers in your field
- rapid publication on acceptance
- support for research data, including large and complex data types
- gold Open Access which fosters wider collaboration and increased citations
- maximum visibility for your research: over 100M website views per year
At BMC, research is always in progress.
Learn more biomedcentral.com/submissions

